\title{
DAMAGE STATES AND CYCLIC BEHAVIOUR OF DRYWALLS INFILLED WITHIN RC FRAMES
}

\author{
A.S. Tasligedik ${ }^{1}$, S. Pampanin ${ }^{1}$ and A. Palermo ${ }^{1}$
}

\begin{abstract}
SUMMARY
Drywalls are the typical infill or partitions used in new structures. They are usually located within structural frames and/or between upper and lower floor slabs in buildings. Due to the materials used in their construction, unlike masonry blocks, they can be considered as light non-structural infill/partition walls. These types of walls are especially popular in New Zealand and the USA. In spite of their popularity, little is known about their in-plane cyclic behaviour when infilled within a structural frame. The cause of this lack of knowledge can be attributed to the typical assumption that they are weak nonstructural elements and are not expected to interact with the surrounding structural system significantly. However, recent earthquakes have repeatedly shown that drywalls interact with the structure and suffer severe damage at very low drift levels. In this paper, experimental test results of two typical drywall types (steel and timber framed) are reported in order to gather further information on; i) their reverse cyclic behaviour, ii) inter-storey drift levels at which they suffer different levels of damage, iii) the level of interaction with the surrounding structural frame system. The drywall specimens were tested using quasi-static reverse cyclic testing protocols within a full scale precast RC frame at the Structures Laboratory of the University of Canterbury.
\end{abstract}

\section{INTRODUCTION}

During the last decades, significant improvements have been achieved in seismic design and retrofit of reinforced concrete (RC) structures (Park and Paulay 1975 [1], Paulay and Priestley 1992 [2]). Lessons learnt from major earthquake events have triggered and/or accelerated new developments in structural engineering. After decades of research and development concentrating on life safety and protection of the structural skeleton from collapse, structural and earthquake engineering is now on the verge of a new seismic design philosophy; to focus on designing low damage earthquake resistant structures (e.g. PRESSS system [3], supplemental damping and base isolation [4], damage resistant technologies [5]). However, there is still a further step prior to achieving an ultimate earthquake resistant solution, which is the protection of the envelope or the non-structural components and elements in a building, including partitions, facades, ceilings, contents and all mechanical services. Following current design methodologies and construction standards, structural systems can properly be designed and constructed to target a desired seismic performance. However, unlike the structural systems, comprehensive guidelines for a performance-based design of non-structural components, with the criteria and objective consistent with those adopted for the structure, are not yet available. The task still requires significant research and development. And in the last decade has received particular attention (e.g. Taghavi and Miranda 2003 [6], Whittaker and Soong 2003 [7], Filiatrault et. al 2010 [8]).

After the Darfield earthquake on the $4^{\text {th }}$ of September 2010, the level of damage associated to the non-structural components well exceeded that observed in the structural components for most of the modern buildings leading to still significant economical losses and downtime. There were buildings in the CBD where the drywalls required replacement after each major earthquake of the Canterbury sequence 20102011 (04 September 2010, 22 February 2011 and 13 June 2011 being the main ones). Typically, the vulnerability of nonstructural components for loss was confirmed and reported by Taghavi and Miranda (2003) [6, 7]; 62\%, 70\% and 48\% of the total cost for office, hotel and hospital buildings are given by the non-structural components respectively.

Non-structural components include a wide range of items. In general and simple terms, they can be classified into three categories:

1. Vertical non-structural elements - i.e. Infill walls, cladding panels

2. Horizontal non-structural elements - i.e. Suspended ceilings

3. Services and components- i.e. water, power/gas lines, machinery, etc.

Among these categories, seismic in-plane behaviour and damage to the vertical elements is mainly controlled by the deformations imposed on the structure. However, for heavy facades or exterior infills (e.g. clay bricks), out-of-plane damage and failure can be triggered by high levels of acceleration too. The horizontal elements, services and components are also more sensitive to acceleration rather than the imposed deformations (NZS1170 [9]).

In order to study the seismic behaviour of the existing nonstructural vertical and horizontal elements and to develop design methods and construction details for the prevention of damage to such components, a research programme has been ongoing at the University of Canterbury since 2010. The reported research covers vertical elements only as part of this wider project where infill walls [10] and cladding panels [11, $12]$ are being investigated.

\footnotetext{
${ }^{1}$ Civil and Natural Resources Engineering Department, University of Canterbury, Christchurch, New Zealand
} 

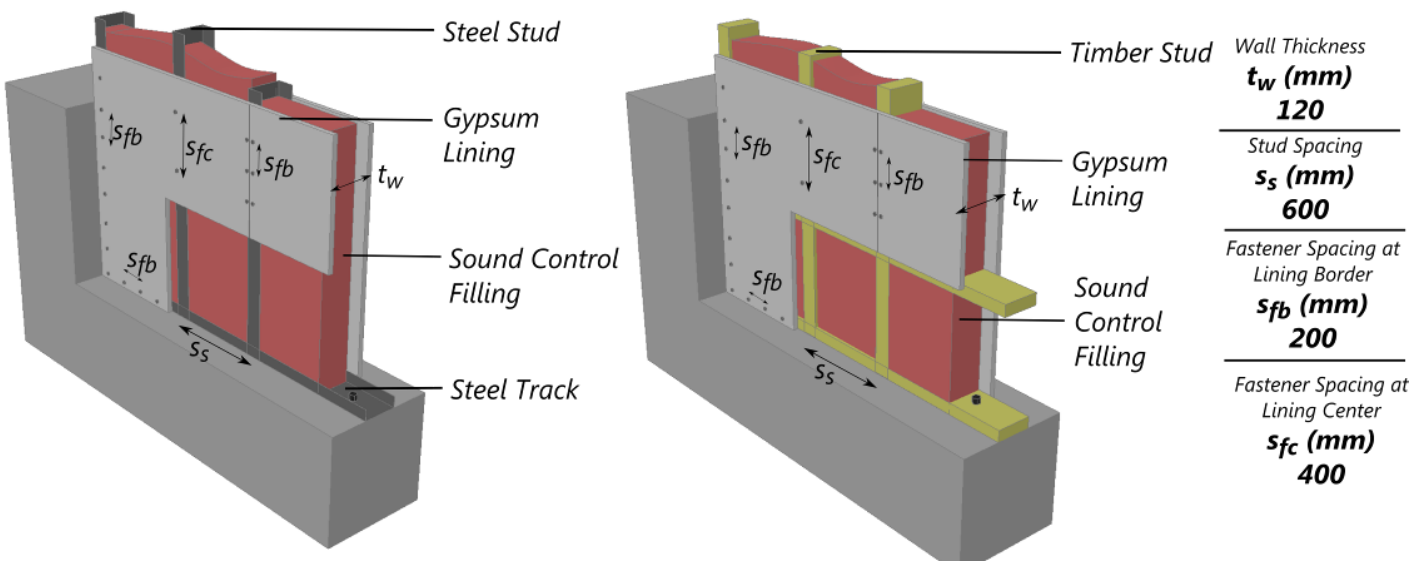

Figure 1: $\quad$ Typical details for steel framed drywall (Left) and timber framed drywall (Right)

In this paper, focus will be given to the recent results on the seismic performance of drywalls designed and installed according to current standards and practice. Two types of drywall specimens were tested, consisting of a steel framed solution and a timber framed solution. The tests were carried out using a quasi-static reverse cyclic loading regime and infilling the specimens within a precast RC frame. In order to be able to carry out a number of tests without damaging the surrounding frame, a low-damage post-tensioned precast concrete frame was utilized.

The drift levels corresponding to each damage state in the drywalls and the interaction with the surrounding frame were observed and reported. It is envisaged that the reported work can be of value not only to have a better understanding of the inherently low seismic performance of existing drywall systems but also for the development of the future technologies to mitigate the seismic damage to such components.

It should be noted that the adopted testing apparatus represents a substantial and important novelty when compared to previous experimental research done using conventional racking tests where lightweight partitions and/or drywalls were typically tested as standalone and without being able to capture their interaction with a surrounding frame.

\section{DRYWALL PRACTICE}

Drywall construction specifications are usually provided by the manufacturer [13]. These specifications need to be compliant with the standard for the finishing of the gypsum linings [14]. Although there are standardized regulations, there is no control during the construction and installation of these types of non-structural wall within the structure, unlike the structural systems themselves. This lack of control can generally be attributed to the misleading definition of nonstructural elements which seems not to trigger requirements for adequate check by the structural engineering community. In addition to that, the lack of technologies and the lack of construction details for damage mitigation of drywalls contribute to the observed poor seismic performance.

In the existing practice, depending on the type of underlying framing, drywalls can be constructed in two ways:

1. Light gauge steel framed drywalls (STFD)

\section{Timber framed drywalls (TBFD)}

Steel framed drywalls are typically adopted within commercial buildings. On the other hand, timber framed drywalls are defined as load bearing elements and are mostly adopted in residential houses as bracing elements. However, their installation in commercial buildings is also allowed. This work focuses on the applications for commercial buildings, where drywalls are not designed to be lateral load resisting elements, but 'only' non-structural elements.

The steel framed drywall construction requires steel studs to be fixed to top and bottom tracks with a single screw (Figure 1). These studs are required to be cut shorter to allow for thermal expansion if possible.

The timber framed drywalls are constructed in the same way as steel framed drywalls. However, timber-to-timber connections are more rigid when compared to the steel counterpart and no thermal expansion provision is required.

In Figure 1, the rendered views of these two types of drywalls are shown with the typical spacing recommended by the specifications.

\section{TEST SETUP}

In order to test the reverse cyclic performance of nonstructural infill walls, a unique full scale test setup was developed. The setup consists of two precast RC columns and beams (C50) connected by two $40 \mathrm{~mm}$ high strength unbounded post tensioning bars (Macalloy 1030). The adoption of this structural system has the following benefits:

1. The precast RC frame behaves elastically and re-centres without undergoing any permanent damage and residual displacement. As such it can be used multiple times with only the infill specimen requiring to be substituted.

2. Since the behaviour of the frame always remains linear elastic, the behaviour of the infill walls can easily be extracted from the global behaviour.

In order to prevent different rates of beam elongation between the beams and the resulting clamping to the columns, pivot points are provided at the lower beam ends. Therefore, the beam elongation only occurs at the upper beam and no clamping occurs on the columns. The resulting frame is connected to the strong floor by pin supports and in order to constrain the frame from deforming out-of-plane, four rollers (two on each side) are placed at the upper beam level. The deformed shape of the completed setup simulates the deformed shape of a flexible structure. The test setup is shown in Figure 2.

The columns and the beams were designed to resist the forces to be exerted by three different infill wall types, planned to be tested as part of the experimental campaign, namely drywalls, unreinforced clay bricks, reinforced hollow masonry. Therefore, the test setup can also be used to test heavier infill wall types in the future. The moment capacity of the connections is similar to that of a typical RC frame and it can 
be controlled by changing the post-tensioning force. Moreover, this particular re-usable test setup required specific connection detailing. The connection exhibits rocking type behaviour, i.e. gap opening/closing, and causes the initial post tensioning forces to increase with the applied drift levels. Due to this increase, an additional confinement requirement, as stated by ETA 07/0046 [15], was supplied in the form of helix shaped confining reinforcement of predetermined size. The details of the beam-column connection are given in Figure 3.

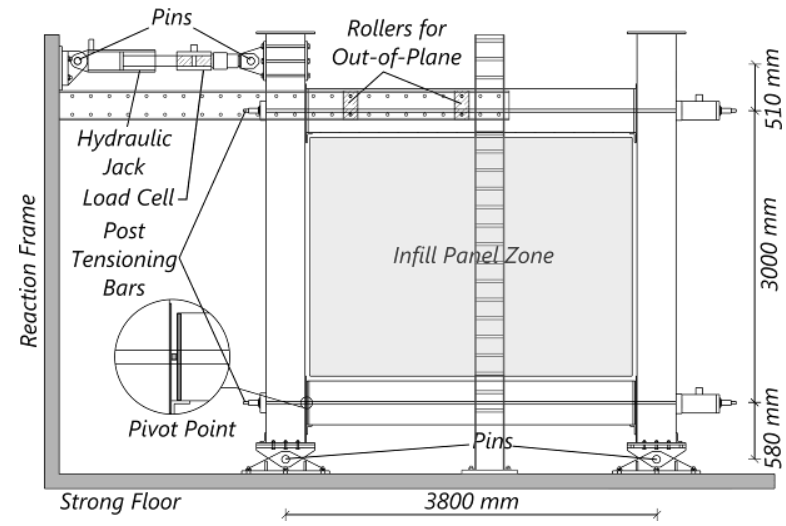

Figure 2: $\quad$ The test setup-front view

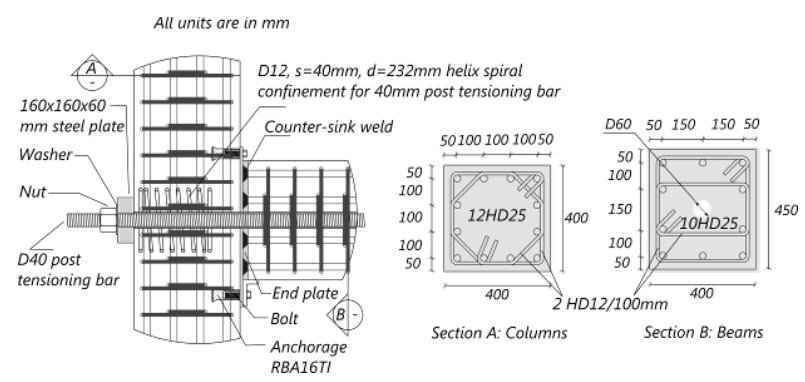

Figure 3: $\quad$ Beam to column connection details

In terms of loading protocol, the recommendations of ACI374.1-05 [16] have been followed with the simplification of not including the intermediate cycles between two consecutive amplitude levels. For the selection of the applied drift levels, ACI374.1-05 requirement is as follows:

$$
1.25 D_{i} \leq D_{i+1} \leq 1.5 D_{i}
$$

$$
\text { where } \quad \begin{array}{ll}
D_{i} & =\text { Previous drift amplitude } \\
& D_{i+1}=\text { Next drift amplitude }
\end{array}
$$

Following the above criterion, the drift history shown in Figure 4 was prepared and used in the tests

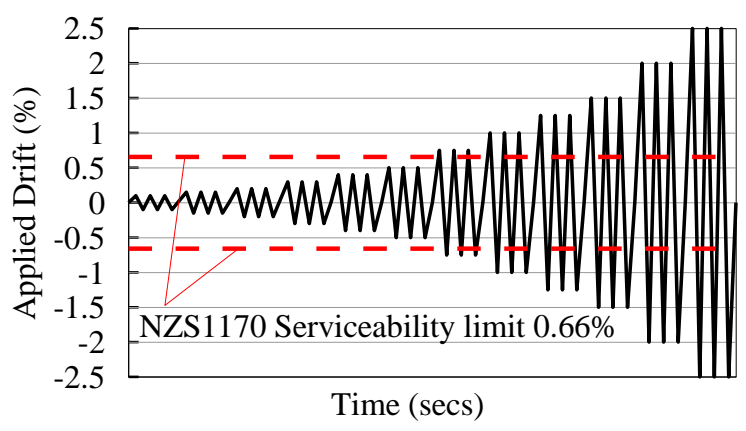

Figure 4: $\quad$ The applied drift history for quasi-static reverse cyclic testing

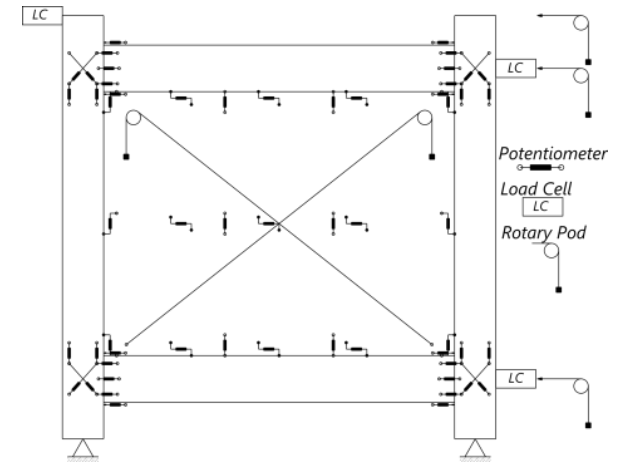

Figure 5: $\quad$ General instrumentation layout

All test specimens were monitored using 3 load cells, 5 rotary pods and 57 potentiometers. Among those, one rotary pod recorded the top deflection at the level of the applied load and two are placed at the beam levels to be able to calculate the inter-storey drift imposed on the structure. The general layout of the instrumentation is shown in Figure 5. It should be noted that this layout is a general scheme developed for all wall types planned in the experimental campaign and not all of the instruments were essential nor used in each test.

\section{TEST SPECIMENS}

As stated previously, two drywalls named as steel framed and timber framed drywalls were tested. Although there are many different options given by the manufacturers, the most typical and the most commonly used were selected. The adopted solutions consisted of a single underlying framing with one layer of gypsum lining on both sides of the wall. In this section, the construction procedure and the installation details for these specimens are reported along with the finishing applied.

\begin{tabular}{|c|c|c|}
\hline where & $F I F$ & $=\underline{\text { Fully } \underline{\text { Infilled }} \text { Frame }}$ \\
\hline & & $=$ Specimen number \\
\hline & Type & $\begin{aligned}= & S T F D \text { for steel framed } \\
& T B F D \text { for timber framed drywall }\end{aligned}$ \\
\hline
\end{tabular}

The notation used in naming the specimens is given below:

$$
\text { FIFi-Type }
$$

\section{Steel Framed Drywall: FIF1-STFD}

For the drywall framing, light gauge steel tracks and stud elements with $30 \times 92 \times 0.55 \mathrm{~mm}$ cross sectional dimensions were used (Figure 6a-b). Standard gypsum wallboards of 13 $\mathrm{mm}$ thickness were chosen as the lining. Three types of anchorage/fastener used in this installation are shown in Figure 6c. Among them, the top two, e.g. steel-to-concrete fasteners, are typically used in fixing the steel elements to the surrounding structural frame. In this particular case, the second option with a predrilled and pre-installed capsule was selected due to ease of removal, which is an HRD frame anchor. The third anchor type is Philips self drilling screws for fixing the steel elements to each other.

The construction procedure starts by fixing the steel tracks to the upper and the lower beams using the steel-to-concrete fasteners (Figure 9-S1). Then the vertical steel studs are fitted into these tracks (Figure 9-S2). In the common practice, the practitioners always fix these studs to the tracks using the self drilling Philips screws shown in Figure 6c. After the studs are fixed to the tracks, linings are attached using the self drilling drywall screws (Figure 9-S3). The construction procedure and the connectivity of the members are shown in Figure 9. 


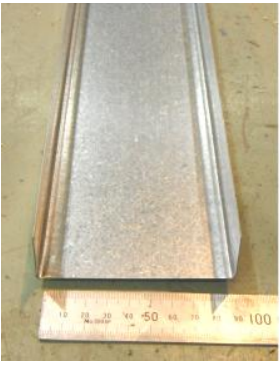

a)

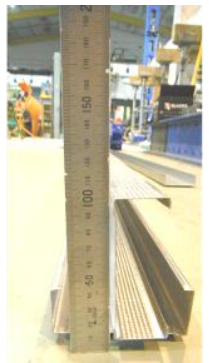

b)

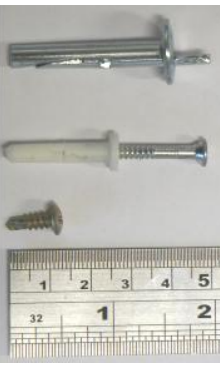

c)
Figure 6: $\quad$ Materials used for the construction of the steel framed drywall, a) Steel track, b) Steel stud, c) Anchors/fasteners from top to bottom: 1\&2-Steel to concrete, 3: Steel to steel

\section{Timber Framed Drywall: FIF2-TBFD}

In this drywall type, timber elements of $45 \times 90 \mathrm{~mm}$ cross sectional dimensions were used for the construction of the underlying framing. The lining type was the same as the one used in the steel framed drywalls (standard gypsum wallboard of $13 \mathrm{~mm}$ thickness). The materials and the anchor types of this drywall are summarized in Figure 7. In Figure 7b, either of the top two anchors is typically used to fix the border timber elements to the surrounding structural frame. In the reported work, the second anchor type was used due to ease of removal, which is a self drilling HUS-H universal screw. The third type of anchors shown, nails, are used to fix the vertical and horizontal timber elements to each other. The last ones are self drilling screws for fixing the gypsum wallboards to the timber framing.
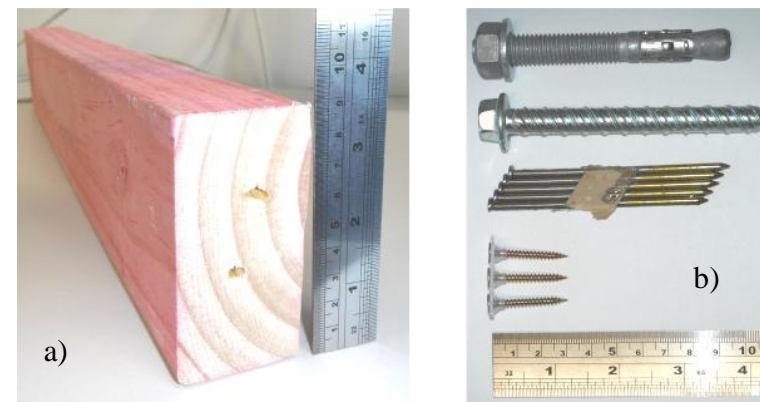

Figure 7: $\quad$ Materials for the construction of timber framed drywall, a) Timber element, b) Used anchorages from top to bottom: 1\&2-timber to concrete, 3-timber to timber, 4-lining to timber

The construction procedure for the timber framed drywalls is very similar to the steel framed counterpart. The procedure starts by fixing the timber elements at the borders (Figure 9T1). Then the vertical elements are installed (Figure 9-T2). After the vertical elements are all in place, the horizontal timber elements are installed (Figure 9-T3). Finally, the linings are attached to the formed timber framing (Figure 9T4). The construction procedure and the connection details are shown in Figure 9.

\section{Finishing of the Drywalls}

Both specimens were finished as per standard commercial practice. For these wall types, the preferred method of finish is a flushed wall surface and square stops at wall ends. The finishing starts with the application of the plaster at the desired location. Then the paper tape is applied to the plaster using another thin layer of the plaster on the tape. The porous structure of the paper tape allows for the penetration of the plaster and provides a tight fixing to the lining. The materials adopted and the installation procedure is shown in Figure 8 . After this phase, the specimens were painted using a thin coat of white paint to allow for ease of visibility for damage and crack marking.

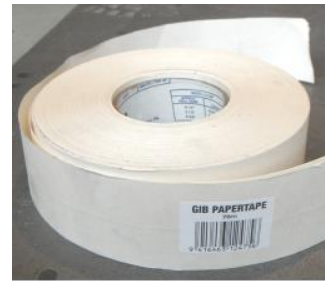

a)

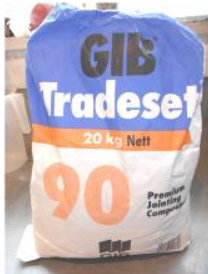

b)

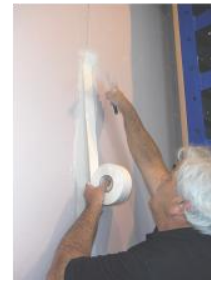

c)
Figure 8: The materials used in finishing the drywalls, a) Paper tape, b) Gypsum plaster, c) Application on the lining interface

\section{TEST RESULTS}

Within the scope of the reported work, three types of tests are herein discussed. Each of these tests will be reported in the related subheadings in this section.

1. $\mathrm{BF}$ (Bare frame)

2. FIF1-STFD (Fully infilled steel framed drywall-Existing practice)

3. FIF2-TBFD (Fully infilled timber framed drywallExisting practice)

\section{Test 1: Bare Frame BF}

As a first test, only the bare frame was tested using the same displacement history in order to characterize the expected elastic behaviour without any damage. The test confirmed the possibility to use the surrounding frame repeatedly for the subsequent tests with infilled walls. The base shear and the post tensioning vs. inter-storey drift curves are shown at column $\mathrm{A}$ in Figure 10 along with the other member end measurements.

\section{Test 2: Fully Infilled Steel Framed Drywall FIF1-STFD}

The steel framed drywall was subjected to the given displacement history in Figure 4. At the initial cycle of $0.1 \%$ drift, there was no apparent damage to the drywall. At $0.15 \%$ drift, hairline cracking at the lining and the RC frame interface was observed for the first time. At $0.2 \%$ drift, the first cracking between the lining interfaces was observed. The observed damage up to this point was within serviceable levels. However, at $0.3 \%$ drift, the cracked lining interfaces deformed more and started to push against each other resulting in bowing at the interface. At $0.3 \%$, also initiation of damage to the fasteners was recorded. Moreover, $0.3 \%$ corresponded to a slight strength drop followed by the ductile post-yield behaviour caused by the loss of the strut action given by the lining. At $0.4 \%$ drift, the bowing damage at the interfaces progressed further and lining A (refer to Figure 11 for the naming of the linings) started to rock on the lower beam causing some toe crushing at the bottom right corner of lining A. Further damage concentrated mainly around lining A and lining B. The force-displacement curve and the recorded measurements are shown in column B in Figure 10. The damage mechanism and damage summary of the test is shown in Figure 11. 

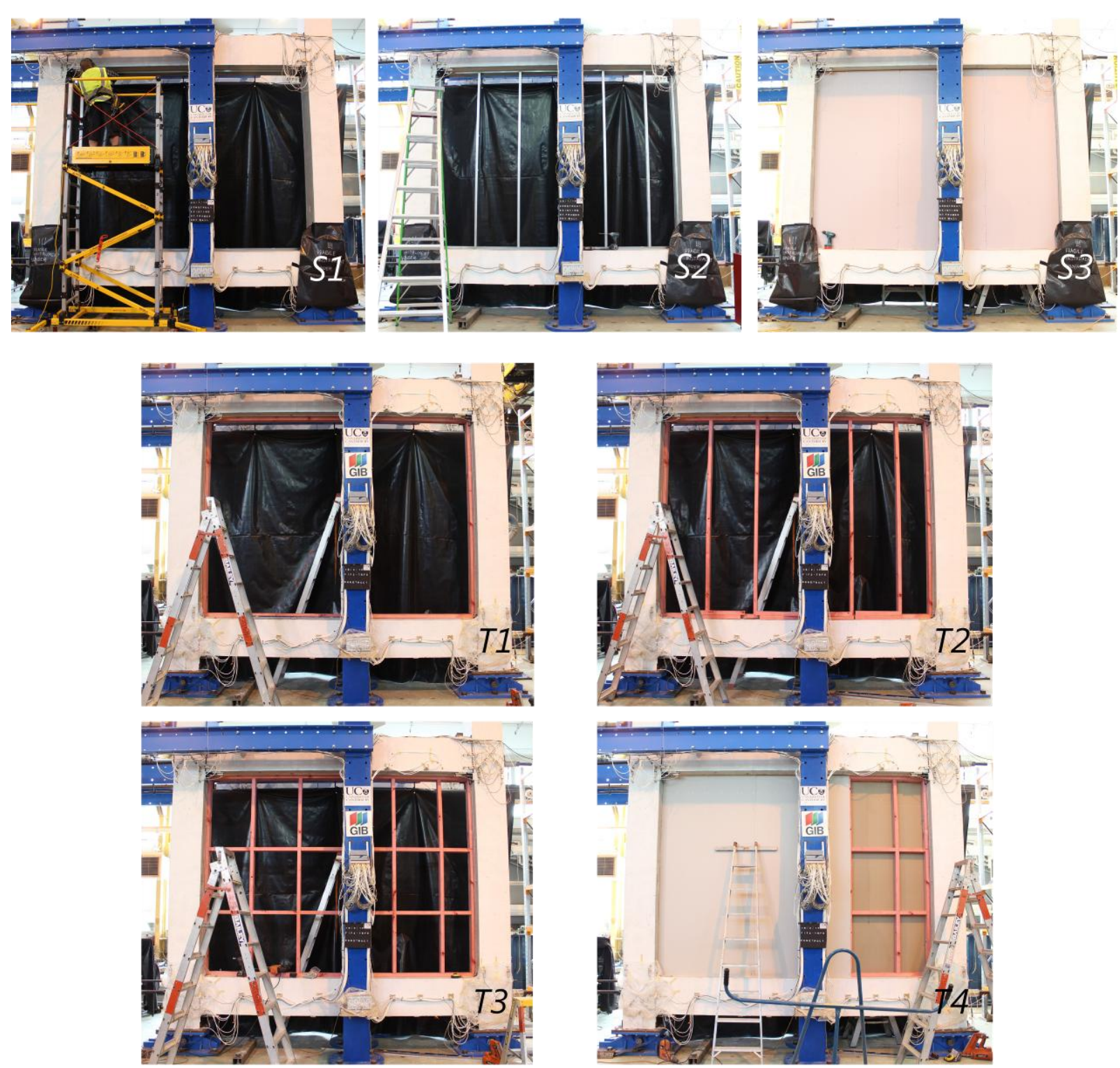

Connectivity of the Members
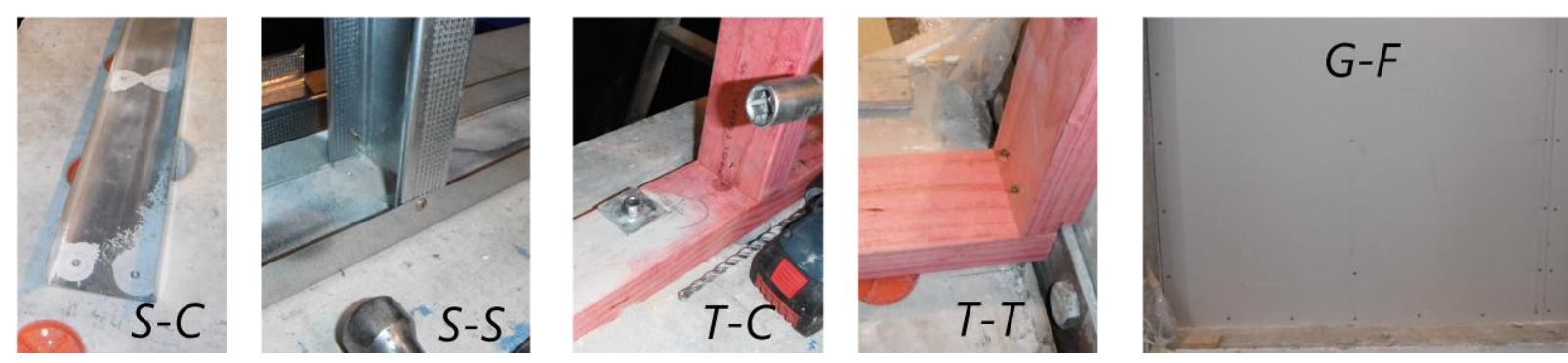

FIF1-STFD

S1-Steel tracks, S2-Steel studs, S3-Gypsum lining

FIF2-TBFD

T1-Border timber, T2-Vertical timber, T3-Horizontal timber, T4-Gypsum lining

Connectivity

$S$-steel, C-concrete, T-timber, G-gypsum lining, F-drywall framing

Figure 9: $\quad$ Construction procedure for the steel (S1-S3) and the timber (T1-T4) framed drywalls and connectivity of the members 
A

Specimen: BF

Lateral Top Displacement (mm)

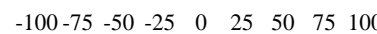

1
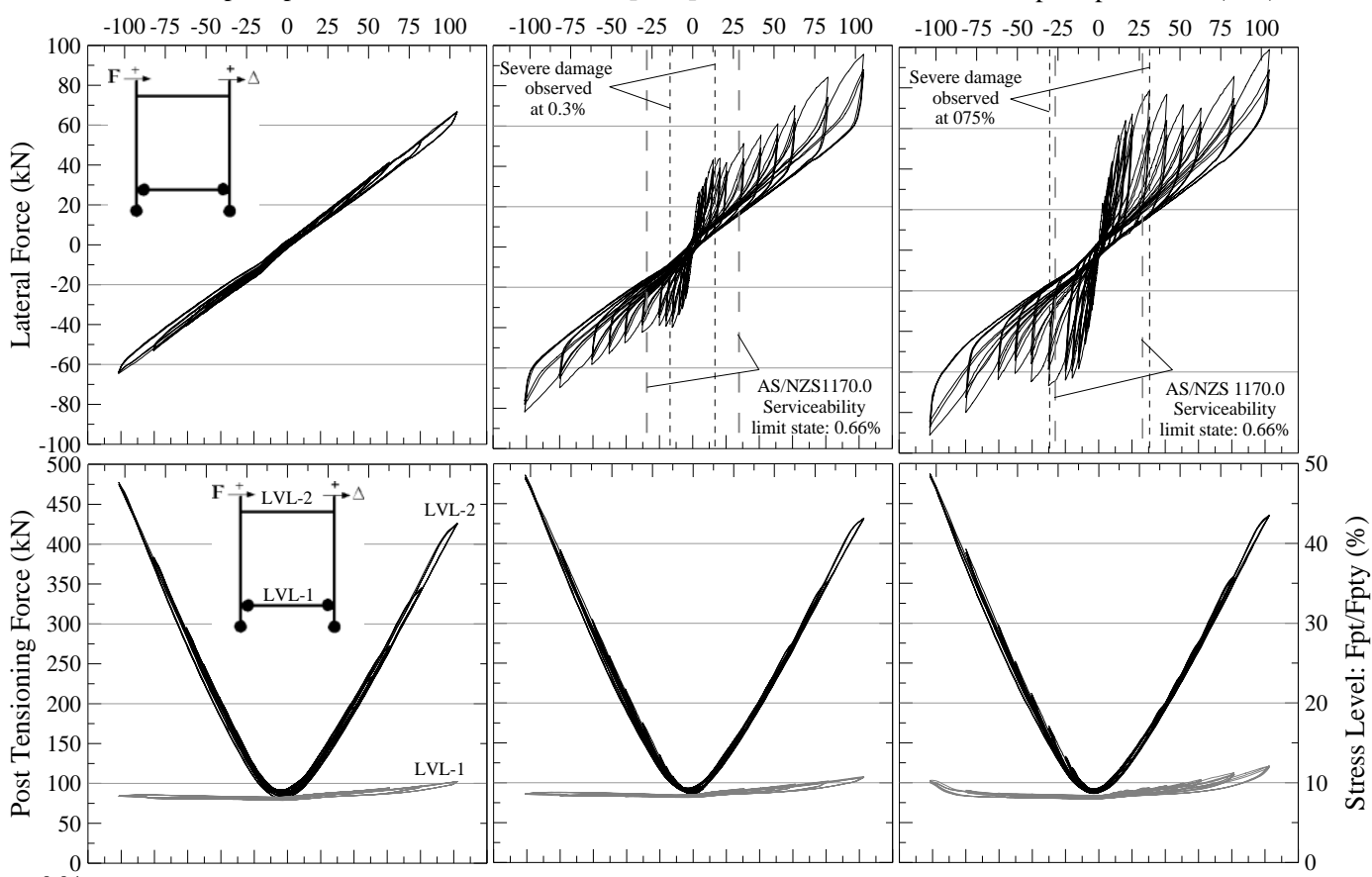

3
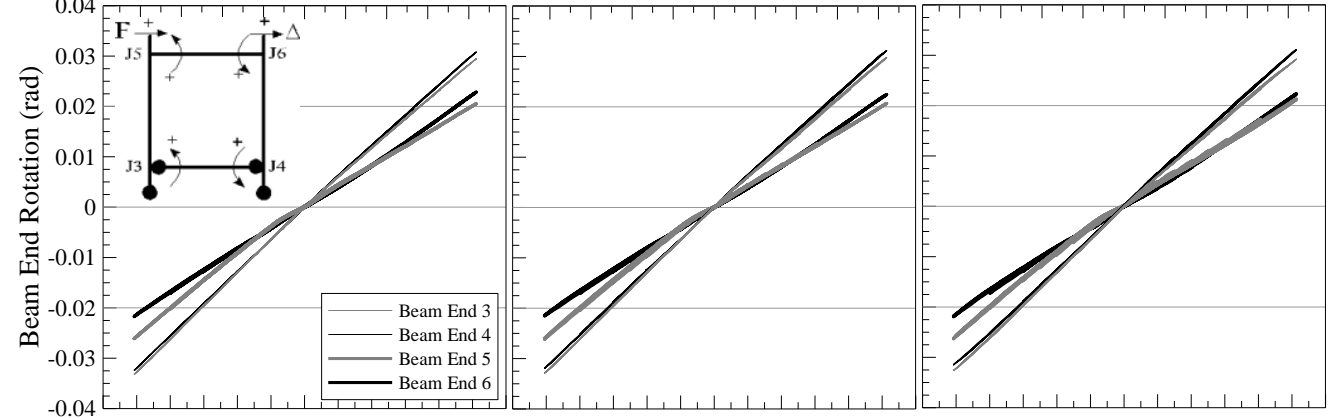

4

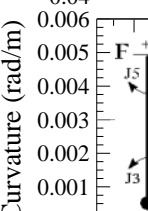

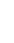

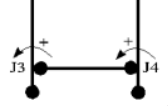

品 -0.001

空 -0.002

《 -0.003

亘 -0.004

肎 -0.005

0.0006

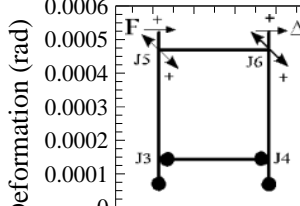

5

๑ั

䆑 -0.0001

政- 0.0002

品 -0.0003

政- -0.0004

$-0.0005$

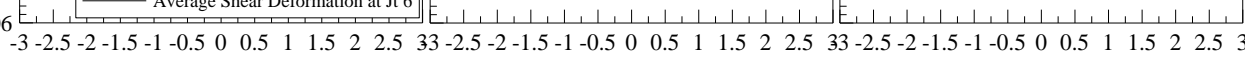

Inter-Storey Drift (\%)

Inter-Storey Drift (\%)

Inter-Storey Drift (\%)

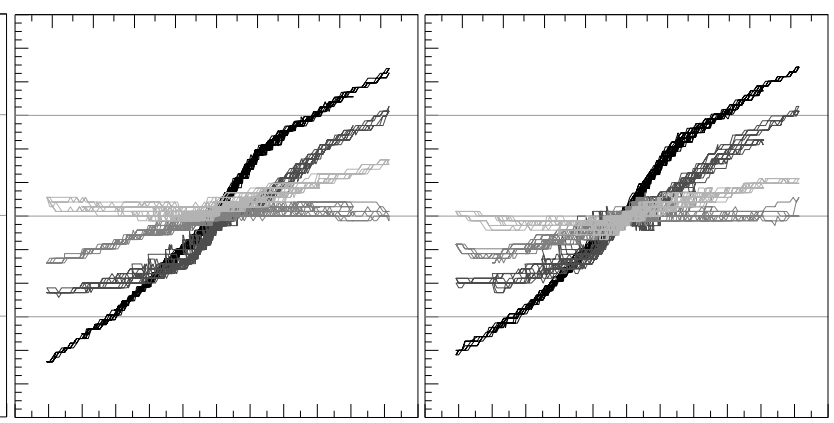

Figure 10: Test results of the three specimens presented in columns A, B, C (Bare Frame, BF; Steel Framed, FIF1STFD; and Timber Framed, FIF2-TBFD)-Note: Lateral top displacement corresponds to the imposed displacements at the level of the actuator 

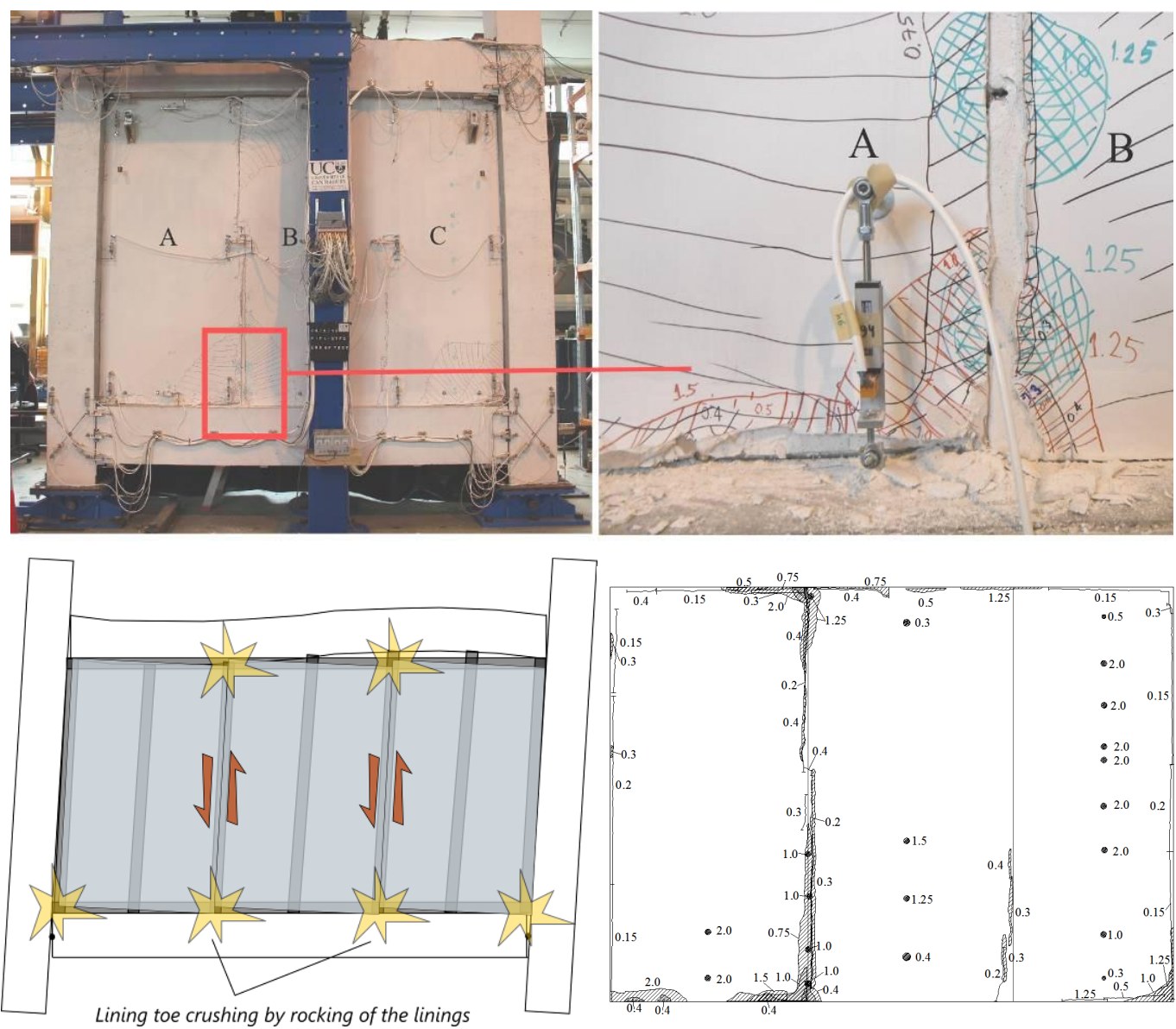

Figure 11: The damage mechanism and summary of observed damage in the Steel Framed specimen FIF1-STFD
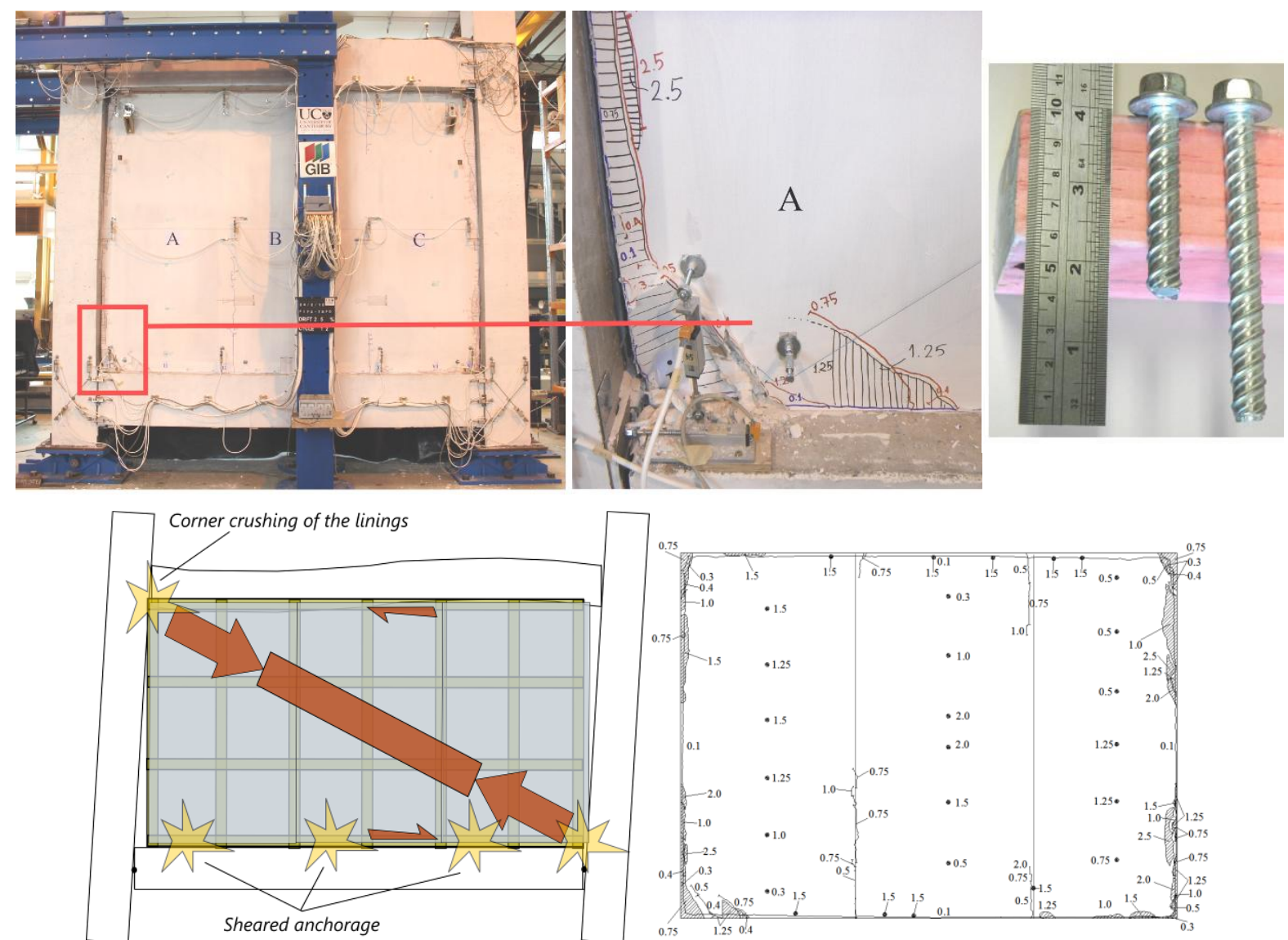

Figure 12: $\quad$ The damage mechanism and summary of observed damage in the timber framed specimen FIF2-TBFD (Top right: sheared timber anchorage compared to an undamaged anchorage) 


\section{Test 3: Fully Infilled Timber Framed Drywall FIF2-TBFD}

The timber framed specimen was subjected to the same displacement history as the other tests. The behaviour of this timber framed specimen was rather different from its steel framed counterpart as observed in column $\mathrm{C}$ of Figure 10. At $0.1 \%$ drift, the first damage was the interface cracking between the linings and the RC frame. After this, at $0.3 \%$, crushing at the bottom right corner of the lining $\mathrm{C}$ initiated (slight at this level). Until $0.75 \%$ drift, all of the existing damage slightly progressed and at $0.75 \%$ drift, severe corner crushing and bowing at linings were observed, which corresponded to a sudden drop in strength followed by brittle behaviour. The damage mechanism and damage summary of this test is shown in Figure 12. After the test was over and while the deconstruction was carried out, it was found out that the 3 anchors fixing the lateral timber member to the lower RC beam had failed in shear at the surface plane of the RC beam (Figure 12). This will be further mentioned in the analysis of results.

\section{ANALYSIS OF RESULTS}

\section{NZS1170.0:2002-General Principles in Structural Design Actions}

One of the most important observations is that when built according to existing construction practice, these walls suffer level of damage which would require repairing intervention, thus exceeding the designed serviceability limit state, at very small drift levels. The steel framed specimen, FIF1-STFD, lost its serviceability conditions at $0.3 \%$ and the timber framed specimen, FIF2-TBFD, lost at $0.75 \%$. According to the Table C1 in NZS1170.0:2002 [9], plaster/gypsum walls (in plane) are expected to suffer lining damage/serviceability condition loss at mid-height deflection of:

$$
\text { Height } / 300
$$

In the tested specimens, the infill wall height was $2550 \mathrm{~mm}$. Therefore, the corresponding mid-height deflection is $2550 / 300=8.5 \mathrm{~mm}$, which corresponds to:

$8.5 / 1275 \times 100 \approx 0.667 \%$ inter-storey drift level

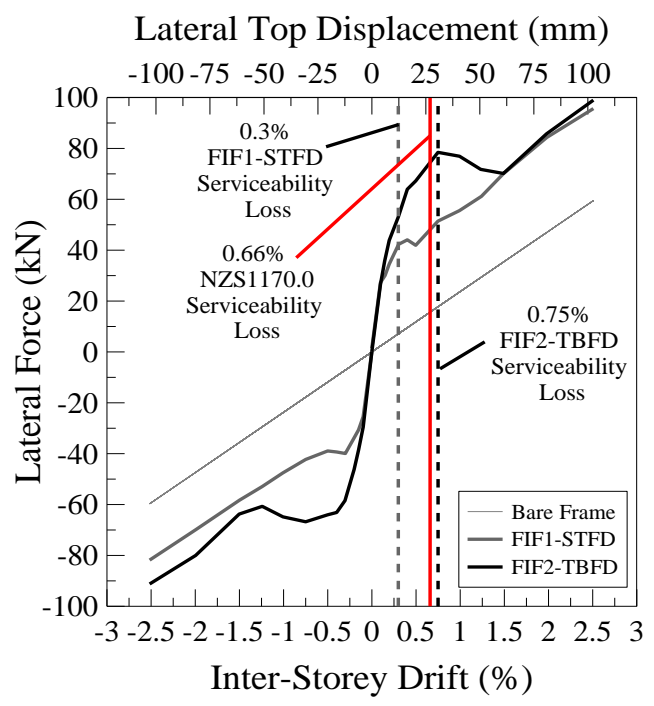

Figure 13: The envelope curves of BF, FIF1STFD and FIF2-TBFD

These values are summarized in the corresponding total force envelope curves in Figure 13. From these, it can be stated that the limit given by the equation (2) does not provide a reliable result for the steel framed specimen, FIF1-STFD. For the timber framed specimen, FIF2-TBFD, it provides a conservative underestimation.

\section{System Interaction}

The existing construction practice is to completely fix the drywall system to the surrounding structural framing. This results in interaction between the drywall and the structural system. Until now, this interaction has generally been assumed to be relatively small and thus somehow negligible, but this is possibly based more on intuitive judgement than on empirical. However, the earthquakes have repeatedly shown that these walls suffer moderate-to-severe damage at very small drift levels, which has also been confirmed by the experiments reported in this paper.

Therefore, the interaction of the two systems is a known fact. This can easily be observed in the recorded measurements. In Figure 10, when compared to the bare frame, it can be observed that the presence of steel framed or timber framed infills does not cause a significant change to the beam end rotations and the column curvatures. However, the joint shear rotation at $2^{\text {nd }}$ level is approximately $20 \%$ higher (Note that there is no moment acting at $1^{\text {st }}$ level joints). In addition, since the bare frame behaves elastically, the behaviour of the infill walls can easily be extracted from the global force-deflection curve (Figure 14), which can analytically be described by Wayne Stewart degrading stiffness hysteresis rule due to the similar pinching of the system (Ruaumoko 2D Carr 2012 [17]). When the envelopes of these curves are considered in this figure, it can be noted that the steel framed specimen's behaviour is rather ductile though there is a slight drop in strength at $0.3 \%$. On the other hand, timber framed specimen has a sudden drop in strength after $0.75 \%$ drift, which is brittle.

The explanation for the difference of the timber framed specimen behaviour can be attributed to the difference between the boundary conditions. Timber framed specimen has more rigid connections among its elements and with the surrounding structural frame (Figure 9). The resulting shear failure observed at the timber-to-RC frame boundary connections at the lower beam can be seen as a proof of such rigidity. Moreover, it can be associated to the brittle behaviour of the timber framed specimen since all three anchors at the lower beam failed in shear (Figure 12).

When the shear capacity of these anchors are examined:

$$
\begin{aligned}
& \tau_{u} \approx 0.62 f_{u f} \text { by NZS3404 [18] } \\
& V_{u}=\tau_{u A}
\end{aligned}
$$

where $\tau_{u}$

$=$ Ultimate shear strength

$f_{u f} \quad=$ Ultimate flexural strength $\approx 480 \mathrm{MPa}$ for mild steel

$V_{u} \quad=$ Ultimate shear capacity per anchorage

A $=$ Shear area of each anchorage $(d=9.5$ $\mathrm{mm}$ )

$$
\begin{aligned}
& \tau_{u} \approx 0.62 \times 480=298 \mathrm{MPa} \text { for mild steel } \\
& \tau_{u} \approx 240 \mathrm{MPa} \text { for the specific anchorage from the } \\
& \text { manufacturer specification } \\
& V_{u}=298 \times 10^{-3} \pi 9.5^{2} / 4=21 \mathrm{kN} \\
& \text { or } V_{u}=240 \times 10^{-3} \pi 9.5^{2} / 4=17 \mathrm{kN} \text { per anchorage }
\end{aligned}
$$

There were 3 anchors connecting the bottom part of the timber framed infill to the RC beam. Therefore, the total shear carried by the three bolts is equal to:

$$
\sum V_{u}=21 \times 3=63 \mathrm{kN}(\text { if mild steel) } \text { or } 17 \times 3=51 \mathrm{kN}
$$



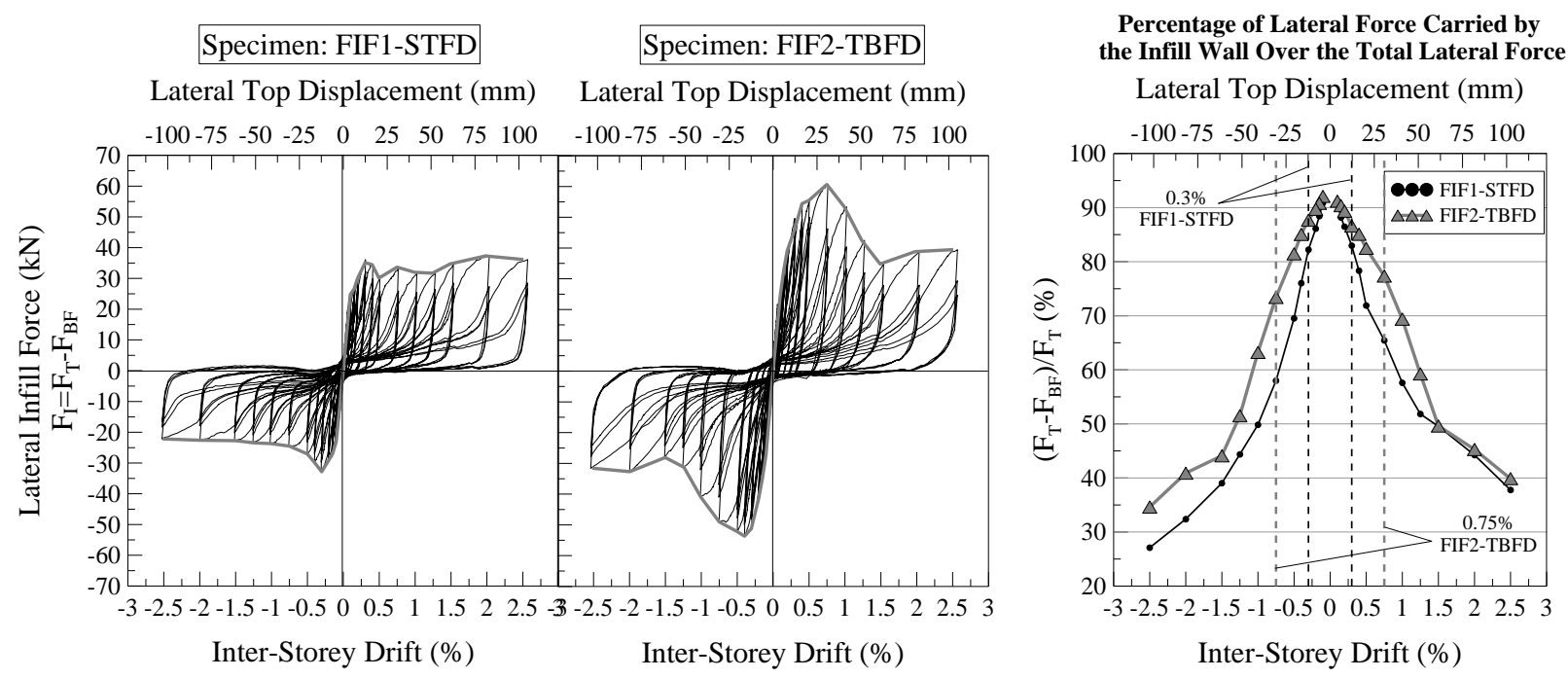

Figure 14: The curves for the lateral force carried by the infill walls $\left(F_{I}=F_{T}-F_{B F}\right) v s$. the inter-storey drift and its percentage over the total lateral force

These numbers are consistent with the measured forcedeflection curve for the timber framed specimen, FIF2-TBFD, in Figure 14. In this figure, the highest force carried by the infill wall approximately corresponds to $60 \mathrm{kN}$. Therefore, it can be deduced that at $0.75 \%$ drift, the boundary anchors between the timber and lower beam progressively started to rupture under shear, which in turn caused a brittle behaviour on the global response and increased deformation demand between the wall and the lower beam. This demand resulted in the crushing of the corner of the linings in the next cycles.

Another important observation can be made when the percentage of the total lateral force carried by the infill wall is plotted versus the imposed drift levels (Figure 14). Although both specimens lost their serviceability at different drift levels, the percentage of the total lateral load resisted by the infill walls are approximately $80 \%$ at these drift levels (82\% for FIF1-STFD, 77\% for FIF2-TBFD). As can be seen in that figure, as higher drifts are applied, this percentage decreases geometrically while following similar curves. However, it should be noted that these values are strongly related to the stiffness and strength of the surrounding frame. Given the characteristics of the testing apparatus, e.g. hinged shim at the first level beam and low level of initial post tensioning, the lateral load capacity of the frame is increasing as the drift increases. In a more standard situation, the "yielding" or nominal lateral load capacity of the bare frame will be achieved more rapidly (e.g. 0.6-1\% drift) and have a less remarked hardening with increased drift level.

\section{Energy Dissipation and Stiffness Degradation}

Because of the inevitable interaction between the infill wall and the structural frame, the drywalls also provided some level of energy dissipation. The equivalent viscous damping $\left(\xi_{e q}\right)$ of the tested specimens were calculated by using the standard area-based method (Eq. 6) suggested in literature (Chopra $2001[19])$ :

$$
\xi_{e q}=\frac{1}{4 \pi} \frac{E_{D}}{E_{S o}}
$$

$$
\text { where } \begin{array}{ll}
E_{D} & =\text { Energy dissipated at a cycle } \\
E_{S o} & =\text { Maximum strain energy at a cycle }
\end{array}
$$

The calculated values for $\xi_{e q}$ and $E_{D}$ are averaged at the applied drift amplitudes and plotted in Figure 16. As can be seen, both specimens have comparable damping and energy dissipation properties with the major difference being at the initial stages until the $1.5 \%$ drift level where the connections of the timber framed specimen contributed the most to the difference. However, these values are very minor and negligible in structures. Moreover, the effective stiffness values were calculated using the points on the total force $\left(F_{T}\right)$ and infill force $\left(F_{I}\right)$ envelope curves of each specimen (Figure 15). Note that a conventional bare frame effective stiffness is usually about $0.3-1 \mathrm{kN} / \mathrm{mm}$ at ultimate. In the reported work, the effective stiffness of the bare frame is $0.55 \mathrm{kN} / \mathrm{mm}$ and thanks to the elastic behaviour of the setup, it remains constant at each displacement stage. Depending on the bare frames of different stiffness, these curves may shift. In the reported study, the bare frame is a very flexible bare frame which is used to observe the wall behaviour and its interaction.

\section{Effective Stiffness vs. Inter-Storey Drift} Lateral Top Displacement (mm)

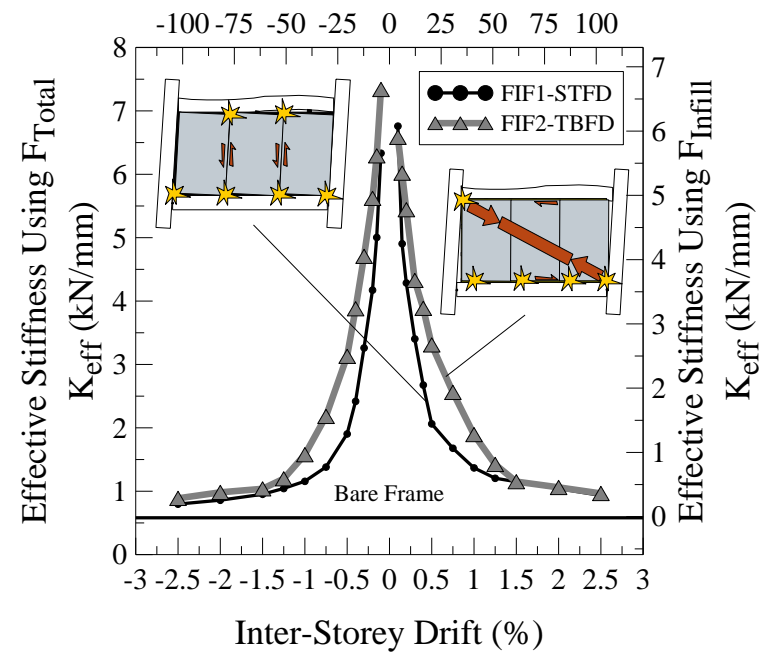

Figure 15: Stiffness degradation with respect to the inter-storey drift, plotted using total lateral force (left axis) and using the lateral force exerted by the infill wall (right axis)

\section{CONCLUSIONS}

It has been confirmed that the drywall systems adopted in current practice for commercial buildings is susceptible to level of damage which would require repairing interventions at low drift levels. The steel framed drywall lost serviceability 


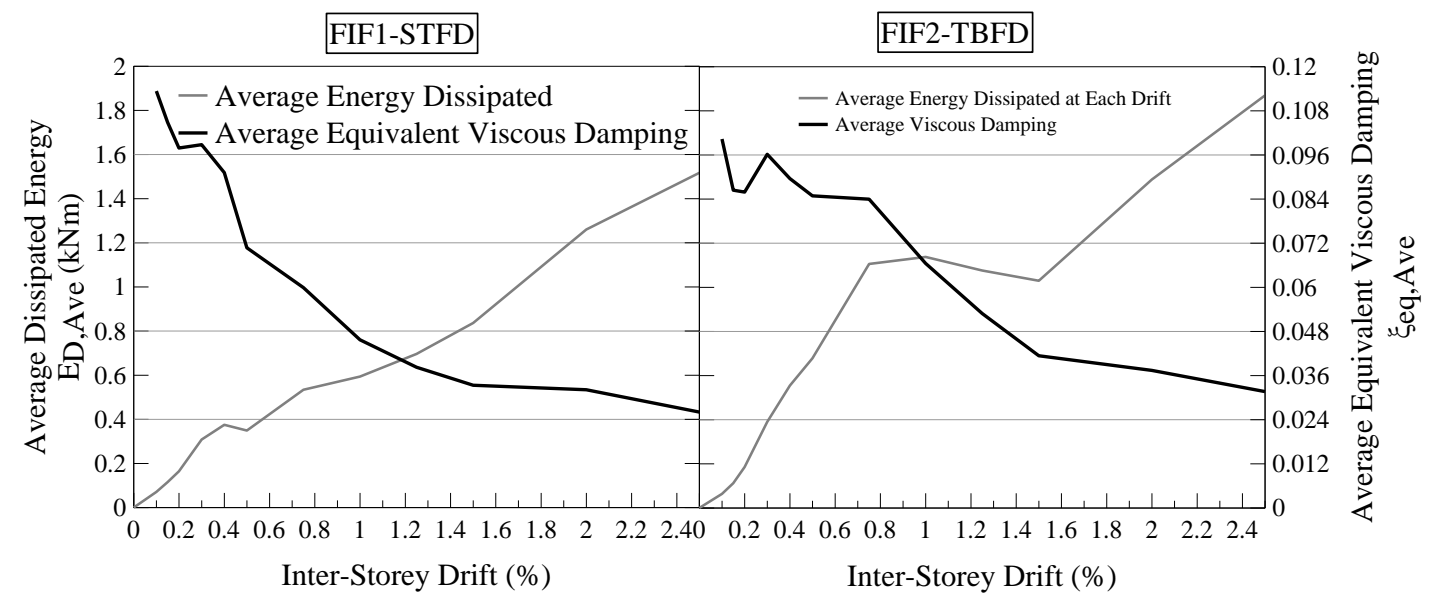

Figure 16: Average viscous damping/dissipated energy with respect to inter-storey drift

condition at $0.3 \%$ inter-storey drift level with a ductile postyield behaviour. On the other hand, the timber framed drywall lost serviceability at the higher drift level of $0.75 \%$ with a brittle behaviour.

The difference in the behaviour of the timber framed drywall can be attributed to the difference in the rigidity of the connections and the resulting shear failure of the lower anchors between the timber frame and the structural frame, which agreed well with the achieved strength value at this specimen. As a result of this, it may be stated that as long as the linings and the timber frame are still intact to sustain the strut action, the strength of timber framed drywalls are governed by the dowel shear capacities given by the anchors. However, for existing and new buildings and depending on the relative stiffness between the drywall and the surrounding structural frame, this brittle behaviour may lead to structural issues to be addressed such as, in the extreme case scenario, soft storey mechanisms (Magenes and Pampanin 2004 [20]). The assumption that these light infill walls does not affect the structural response may, in general terms, need to be revisited. On the other hand, in steel framed drywalls, the rotational degree of freedom of steel studs about the single screw anchors on the top and the bottom tracks imposes significant movement to the lining interfaces prior to damaging the boundary anchors. Therefore, their behaviour seems to be ductile compared to that observed in the timber framed drywalls.

The above mentioned difference also showed that in the table C1 of AS/NZS 1170.0:2002-Plaster/Gypsum walls (in-plane)-, the generalized serviceability limit state criterion might need to be revisited. The criterion in the Standard states the serviceability limit as the mid-height deflection of height/300. Although the test setup is more flexible than a typical multistorey frame, this formula overestimates the limit state for the steel framed drywalls, which are the common drywall partition type in the commercial construction. For steel framed drywalls, this criterion may need to be modified. On the other hand, the existing criterion gave a reasonably accurate result for the timber framed drywalls. Therefore, it may be more realistic to give limit states for these two different types of drywalls under two different categories. This may require further testing and numerical study in order to strengthen the conclusions.

Moreover, the tests once again showed that these nonstructural walls are extremely susceptible to drift and suffer significant damage at very low drift levels (0.3\%-0.75\%). Considering that the costs associated with the loss of nonstructural components are much higher than the structural components [6, 7], it is very important to develop technological solutions to minimize the damage to nonstructural walls, which are under development and testing at the University of Canterbury.

\section{ACKNOWLEDGMENTS}

The authors would like to express their gratitude to the Foundation for Research, Science and Technology (FRST) and the Ministry of Science and Innovation (MSI) for supporting this research as part of the projects "Non-Structural Elements in Building Seismic Performance" and "Improved Seismic Performance of Non-Structural Elements" respectively. The authors also wish to extend their acknowledgements to Hans Gerlich and Bruce Levey (Winstone Wallboards Ltd.) for providing the material, labour and practical advice during the preparation of the reported drywalls.

\section{REFERENCES}

1 Park, R., Paulay, T. (1975). "Reinforced Concrete Structures": John Wiley and Sons, Inc.

2 Paulay, T., Priestley, M.J.N. (1992). "Seismic Design of Reinforced Concrete and Masonry Buildings": John Wiley and Sons, Inc.

3 NZCS (2010). "PRESSS Design Handbook" (Ed. Pampanin S.). NZ Concrete Society Inc.

4 Christopoulos, C., and Filiatrault, A. (2006).”Principles of Passive Supplemental Damping and Seismic Isolation". IUSS Press. First edition. Pavia, Italy.

5 Buchanan, A.H., Bull, D., Dhakal, R., MacRae, G., Palermo, A., Pampanin, S. (2011). "Base Isolation and Damage-Resistant Technologies for Improved Seismic Performance of Buildings". A Report Written for the Royal Commission of Inquiry into Building Failure Caused by the Canterbury Earthquakes. Research Report 2011-02, August 2011.

6 Taghavi, S., Miranda, E. (2003). "Response Assessment of Nonstructural Building Elements". Pacific Earthquake Engineering Research Center.

7 Whittaker, A. S., Soong, T.T. (2003). “An Overview of Nonstructural Components Research at Three U.S. Earthquake Engineering Research Centers". Paper presented at the ATC-29-2 Seminar on Seismic Design, Performance, and Retrofit of Nonstructural Components in Critical Facilities, Los Angeles, California, October 23-24, 2003.

8 Filiatrault, A., Mosqueda, G., Retamales, R., Davies, R., Tian, Y., Fuchs, J. (2010). "Experimental Seismic Fragility of Steel Studded Gypsum Partition Walls and Fire Sprinkler Piping Subsystems". Paper presented at the ASCE Structures Congress, Orlando, Florida, the USA, May 12-15, 2010. 
9 AS/NZS 1170.0 (2002). "AS/NZS1170.0:2002, Part 0: General Principles, Structural Design Actions". The Joint Australian/New Zealand Standard by Committee BD-006.

10 Tasligedik, A.S., Pampanin, S., Palermo, A. (2011). "Damage Mitigation Strategies of 'Non-Structural' Infill Walls: Concept and Numerical-Experimental Validation Program". Proceedings of the 9th Pacific Conference on Earthquake Engineering, Auckland, New Zealand, April 14-16, 2011.

11 Baird, A., Palermo, A., Pampanin, S., Riccio, P., Tasligedik, A.S. (2011). "Focusing on Reducing the Earthquake Damage to Facade Systems". Bulletin of the New Zealand Society for Earthquake Engineering, 44(2).

12 Baird, A., Palermo, A., Pampanin, S. (2012). "Understanding Cladding Damage: A Numerical Investigation into a Christchurch Earthquake Case Study". Proceedings of the 2012 NZSEE Conference, Christchurch, New Zealand, April 13-15, 2012.

13 GIB (2010). "GIB site guide for residential and commercial installations: CBI 5113". Manufacturer's installation guidelines- www.gib.co.nz.

14 AS/NZS 2589 (2007). "Gypsum linings-application and finishing". The Joint Australian/New Zealand Standard by Committee BD-011.
15 Macalloy (2007). "ETA-07/0046: European technical approval for macalloy 1030 post tensioning kit". European Technical Approval by the European Organisation for Technical Approvals (EOTA), Kent/United Kingdom

16 ACI (2005). "ACI374.1-05: Acceptance Criteria for Moment Frames Based on Structural Testing and Commentary". American Concrete Institute.

17 Carr, A.J. (2012). "Ruaumoko: Inelastic Dynamic Analysis Software". University of Canterbury, Christchurch, New Zealand.

18 NZS 3404.1 (1997). "NZS3404.1:1997, Part 1: Steel Structures Standard". New Zealand Standard by Committee P3404.

19 Chopra, A.K. (2001). "Dynamics of Structures: Theory and Applications to Earthquake Engineering (2nd ed.)". New Jersey: Prentice Hall.

20 Magenes, G., Pampanin, S. (2004). "Seismic Response of Gravity-Load Design Frames with Masonry Infills". Proceedings of the 13th World Conference on Earthquake Engineering, Vancouver, B.C., Canada, August 1-6, 2004. 